\title{
Delavnica o modeliranju širjenja bolezni in škodljivcev v evropskih gozdovih
}

\section{Nikica OGRIS*}

Na delavnici, ki je potekala $\mathrm{v}$ mestu Joensuu na Finskem od 19. do 20. februarja $2014 \mathrm{v}$ organizaciji projekta ISEFOR*, smo obravnavali modele, ki napovedujejo širjenje invazivnih škodljivcev in bolezni gozdnega drevja. $\mathrm{V}$ okviru projekta so razvili sedem modelov za naslednje škodljive organizme: (1) borova ogorčica, Bursaphelenchus xylophilus (Steiner \& Buhrer) Nickle; (2) jesenov ožig, Chalara fraxinea T. Kowalski; (3) borov smolasti rak, Fusarium circinatum Nirenberg \& O'Donnell; (4) rdeča pegavost borovih iglic, Dothistroma septosporum (Dorog.) M. Morelet; (5) sibirski veščec, Dendrolimus sibiricus Chetverikov; (6) jesenov krasnik, Agrilus planipennis Fairmaire; (7) jelševa fitoftora, Phytophthora alni Brasier \& S.A. Kirk.

Omenjene modele sta razvila prof. dr. Timo Pukkala in dr. Timo Möykkynen iz Univerze Vzhodne Finske. Vsi modeli so celični avtomati (CA), ki se pogosto uporabljajo za simulacijo širjenja gozdnih požarov in širjenja bolezni. Osnovne značilnosti $\mathrm{CA}$ so ( $\mathrm{Li}-$ chtenegger, 2005): prostor in čas sta diskretna, mrežo celic (pogostokrat dvodimenzionalna) opazujemo v določenih časovnih korakih; pri vsakem časovnem koraku vsaka celica zavzame določeno stanje izmed končnega števila stanj; stanje celic se spreminja v skladu s predpisanimi determinističnimi pravili, ki veljajo za vse celice in vse časovne korake: stanje celice $\mathrm{v}$ določenem časovnem koraku je odvisno samo od njenega stanja in stanja sosednjih celic iz prejšnjega koraka ali korakov.

Vsak CA je definiran s štirimi med seboj odvisnimi elementi: geometrijo mreže celic, sosedstvom celice, številom stanj, ki jih posamezna celica lahko zavzame, in pravilom za določitev novega stanja celice (Hayes, 1984). Vsi modeli, ki smo jih obravnavali na delavnici, imajo kvadratno geometrijo celice velikosti $1 \mathrm{~km}^{2}$. Sosedstvo celic je razširjeno Moorovo, kjer se v soseščino šteje večje število celic (Packard in Wolfram, 1985). Modeli razlikujejo naslednja stanja celic: zdravo, okuženo ali napadeno (št. okuženih ali napadenih dreves $\mathrm{v}$ celici), vsa gostiteljska drevesa so mrtva. Vsi modeli so stohastični, kar pomeni, da je njihova napoved verjetnostna in vsaka simulacija predstavlja samo en verjetnostni izid stohastičnega procesa. Zato moramo vsak model simulirati večkrat, da dobimo karto tveganja, kar je glaven rezultat omenjenih modelov. Karta tveganja podaja verjetnost, da je določen škodljivec ali bolezen dosegla določeno mesto $\mathrm{v}$ določenem času.

Modeli so razviti v obliki uporabniške aplikacije v programskem jeziku FORTRAN. V uporabniškem grafičnem vmesniku lahko nastavimo parametre modela, določimo imena vhodnih in izhodnih datotek (slika 1). Vhodne in izhodne datoteke so v ASCII formatu. Vsak model ima drugačne vhodne parametre, tukaj jih navajamo za borovo ogorčico. Vhodi: raster rabe tal, raster gostote populacije ljudi, raster deleža rdečega bora (gostitelj), raster nadmorske višine, seznam vstopnih mest. Parametri: največja in srednja razdalja letenja vektorja, največja in srednja razdalja transporta napadenega materiala od mesta vnosa, največje število napadenih dreves na celico, število saprofitskih primerov na celico, število novih napadenih hroščev na saprofitskem primeru, zvišanje povprečne temperature zraka, količnik za število vnosov, število let za posamezno simulacijo in število simulacij. Izhodi modelov vključujejo karto verjetnosti napada ali okužbe, karto mrtvih dreves, karto časa okužb ali napadov, časovni potek širjenja, površina in delež napadenih ali okuženih modelnih celic.

Ko smo zagnali simulacijo za borovo ogorčico za primer širjenja v Južni Finski, smo upoštevali 13 vstopnih mest, posamezna simulacija je trajala 20 let, naredili smo pet ponovitev in domnevali smo, da se bo povprečna letna temperatura zvišala za $4{ }^{\circ} \mathrm{C}$ (ostali parametri modela so navedeni v sliki 2). Rezultati so pokazali, da bi v 20. letih borova ogorčica napadla povprečno $64,2 \%$ površin v Južni Finski, kjer raste rdeči bor (slika 3).

Model se vedno razvije za izpolnjevanje določenega namena in doseganje izbranega cilja, tj. pojasnjevanje določenega problema. Vse $\mathrm{v}$ modelu je podrejeno njegovemu namenu, npr. kompleksnost, število vključenih spremenljivk, prostorska in časovna ločljivost. Zaradi sposobnosti modelov, da simulirajo različne procese, je z njimi mogoče napovedovati, kako bi se določen proces razvijal ob izbranih vhodnih pogojih. Rezultat je sicer bolj ali manj verjeten, uporaba modelov pa je pomembna zaradi pridobivanja koristnih informacij in novega znanja (Jørgensen in Bendoricchio, 2001). Modeli, ki so jih razvili v projektu ISEFOR, so dovolj fleksibilni, da z njimi lahko pripravimo verjetnostno karto širjenja izbranih škodljivcev in bolezni $v$ Evropi ali v posamezni državi, saj lahko vhodne podatke zamenjamo $z$ natančnejšimi za drugačno območje. Edino, kar ne moremo spreminjati so procesi širjenja, ki so zakodirani v programsko opremo. Ocenjujemo, da so lahko predstavljeni modeli kakovostno orodje za pripravo analiz tveganj izbranih škodljivih organizmov (angl. Pest Risk Analysis), kjer se odločamo, ali bomo regulirali tujerodne škodljive organizme, da bi preprečili njihovo širjenje in posledično gospodarsko škodo.

*ISEFOR je bil projekt sedmega okvirnega programa FP7 2007-2013 KBBE 2009-3, pogodba št. 245268, koordinator projekta je bil prof. dr. Stephen Woodward. Akronim projekta ISEFOR je okrajšava za naslov "povečanje trajnosti evropskih gozdov" (angl. Increasing Sustainability of European Forests). Projekt je naslavljal naslednje probleme: (1) vpliv podnebnih sprememb na vitalnost gozdov; (2) večanje tveganja zaradi tujerodnih invazivnih škodljivcev in bolezni; (3) 
sprememba tveganja domorodnih škodljivcev in bolezni ali tujerodnih vrst, ki so že prisotne v Evropi. Modelarja T. Pukkala in T. Möykkynen sta tesno sodelovala s strokovnjaki, ki imajo obširno znanje o biologiji izbranih boleznih in škodljivcih, to so: Christelle Robinet (borova ogorčica), Thomas Kirisits in Jan Stenlid (jesenov ožig), Andrea Vannini in Alberto Santini (jelševa fitoftora), Stephen Woodward (rdeča pegavost borovih iglic), Paolo Capretti (borov smolasti rak), Dmitri Musolin (sibirski veščec), Marc Kenis (jesenov krasnik).

\section{Viri}

Hayes B. 1984. Computer recreations: the cellular automaton offers a model of the world and a world unto itself. Scientific American, 250, 3: 12-21
ISEFOR - Increasing Sustainability of European Forests. http://www.isefor.com

Jørgensen S.E., Bendoricchio G. 2001. Fundementals of ecological modelling. $3^{\text {rd }}$ edition. Elsevier: $530 \mathrm{str}$.

Lichtenegger K. 2005. Stochastic cellular automata models in disease spreading and ecology. Diploma thesis. Graz, Karl-Franzens Universität Graz, Faculty of science: 96 str.

Packard N.H., Wolfram S. 1985. Two-dimensional cellular automata. Journal of Statistical Physics, 38: 901-946

*Gozdarski inštitut Slovenije, Večna pot 2, 1000 Ljubljana nikica.ogris@gozdis.si

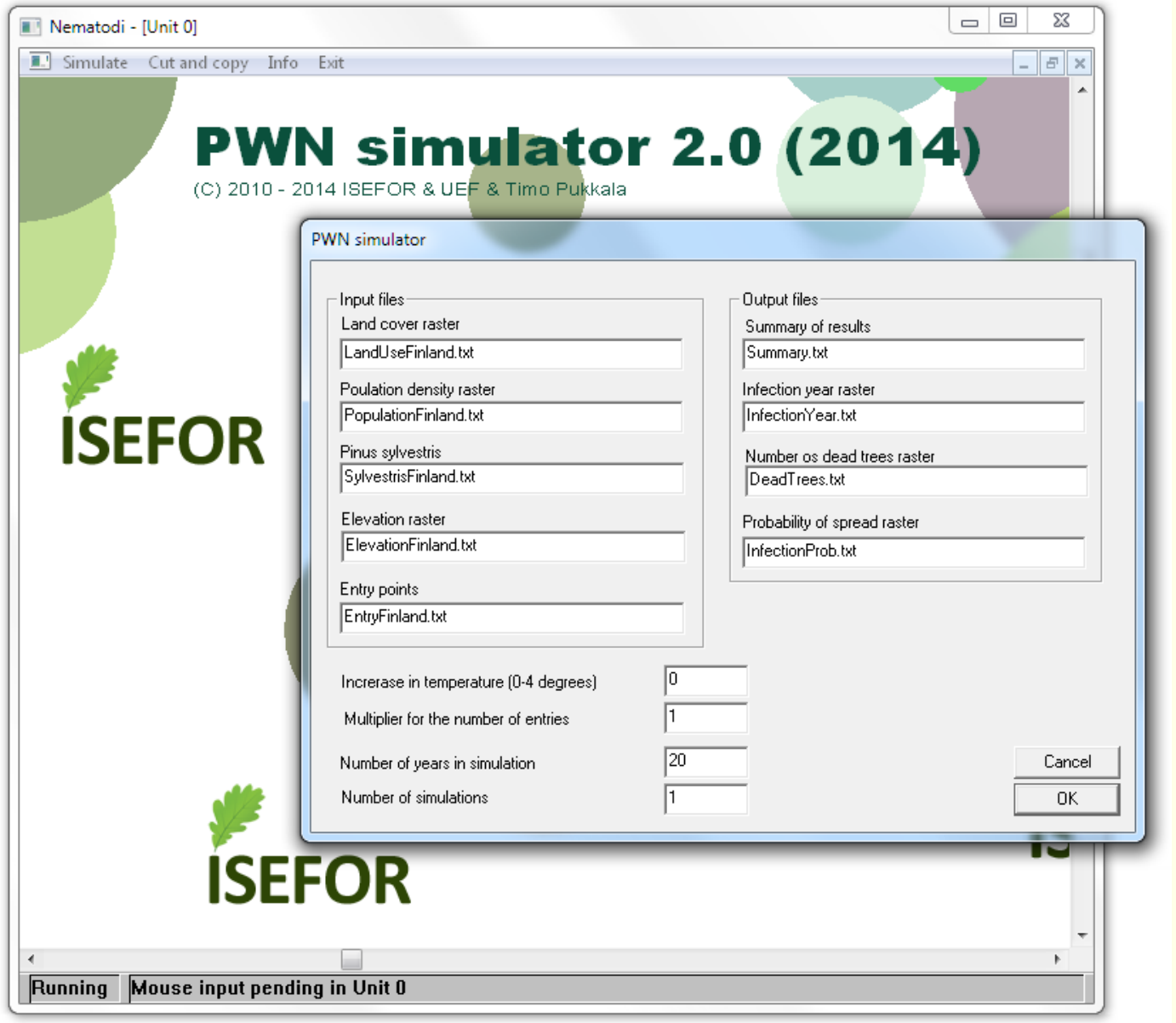

Slika 1: Obrazec za nastavitve parametrov simulacije širjenja borove ogorčice

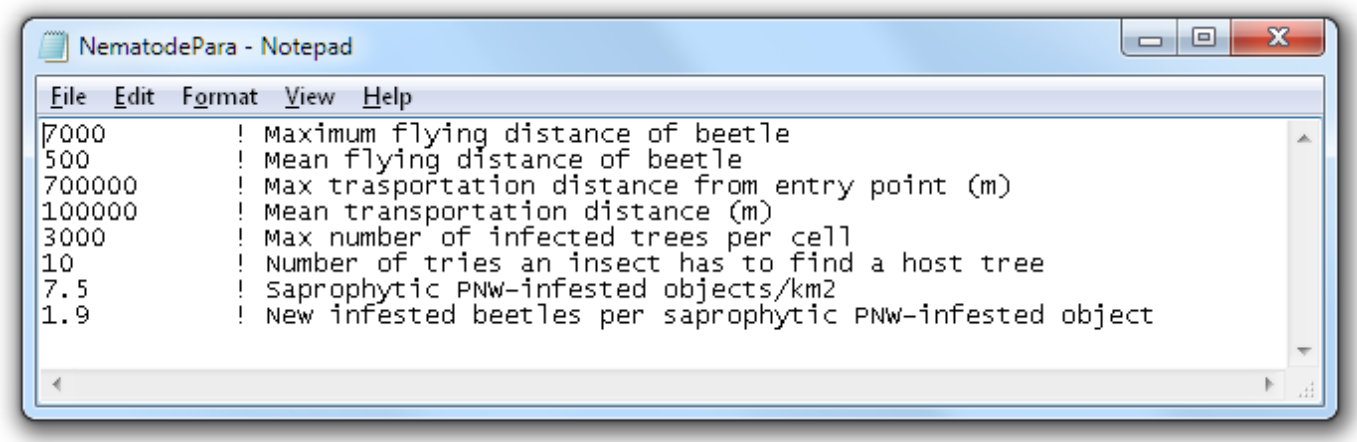

Slika 2: Privzeti parametri za model širjenja borove ogorčice 


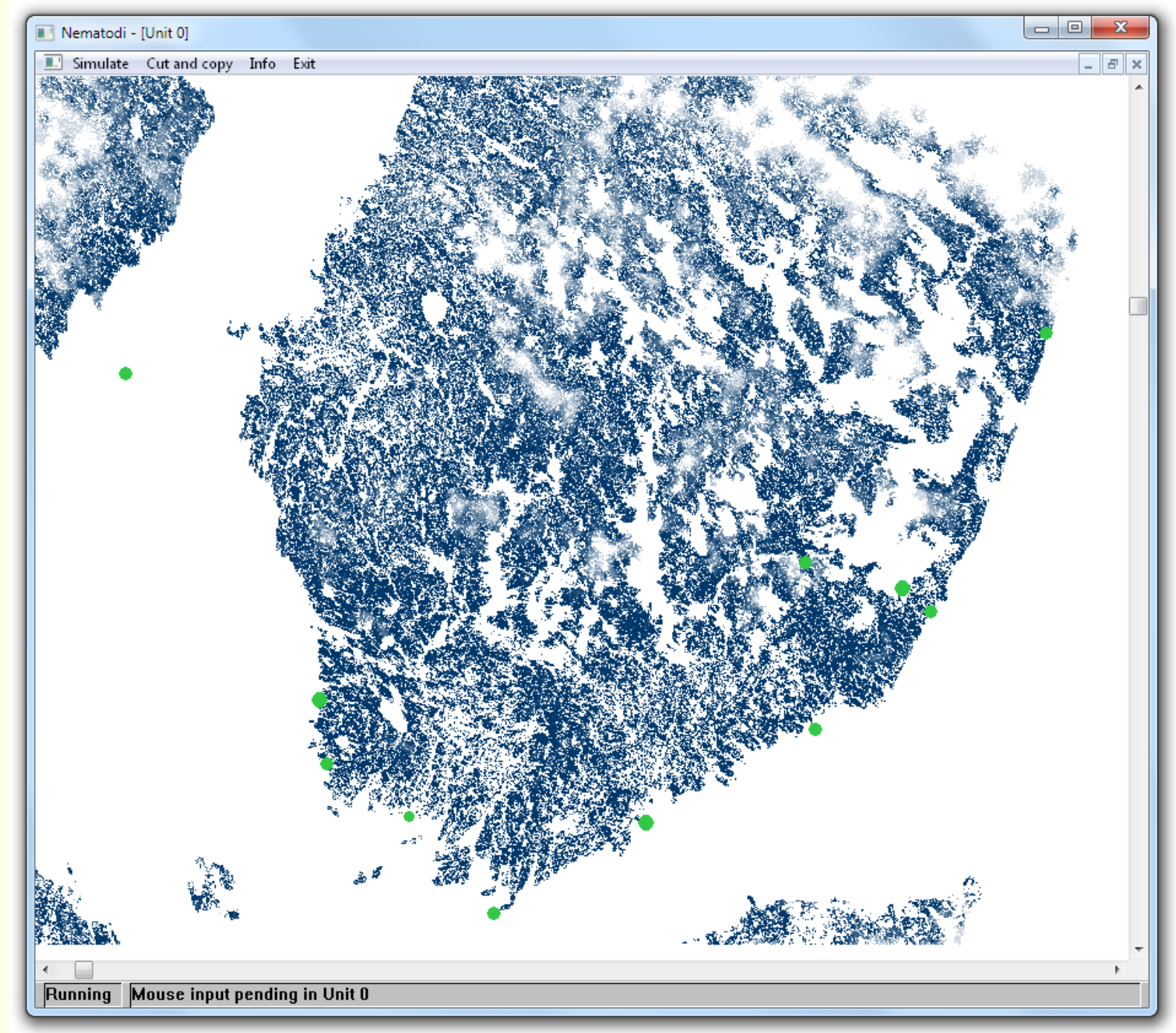

Slika 3: Primer karte tveganja širjenja borove ogorčice za Južno Finsko (13 vstopnih mest, trajanje simulacije 20 let, 5 ponovitev, povprečna letna temperatura $+4^{\circ} \mathrm{C}$ ) 